\title{
Three-dimensional hydrodynamics numerical of wind-driven circulations in Danjiangkou Reservoir
}

\author{
Jie Zhu ${ }^{1}$, Jin Quan ${ }^{2, a}$, Xiaohui Lei ${ }^{2}$, Xia Yue ${ }^{1}$, Yang Duan ${ }^{3}$ \\ ${ }^{1}$ College of Architecture and Civil Engineering, Beijing University of Technology, Beijing 100022, China; \\ ${ }^{2}$ China Institute of Water Resources and Hydropower Research, Beijing 100038 , China \\ ${ }^{3}$ State Key Laboratory of Environmental Protection, Environment Planning and Policy Simulation, Chinese Academy for Environment \\ Planning, Beijing 100012, China
}

\begin{abstract}
This paper focuses on the analysis of the flow field of Danjiangkou Reservoir under the action of wind stress. Based on the analysis of the annual wind field data of Danjiangkou Reservoir, the three-dimensional hydrodynamic model of Danjiangkou Reservoir was established. The distribution of water flow field in the reservoir area under five different wind directions and two different wind speeds was studied. The simulation results were compared with the flow field without wind. The results show that when the wind speed in the reservoir area is $3.3 \mathrm{~m} / \mathrm{s}$, the surface velocity and flow direction change less under the same wind conditions as the potential flow direction. Under the wind condition opposite to the potential flow direction, the reservoir area is locally generated. The small circulation and surface flow are more disordered; when the wind speed reaches $10.0 \mathrm{~m} / \mathrm{s}$, under the same wind condition as the potential flow direction, the surface velocity of the reservoir area increases significantly. Under the wind condition opposite to the direction of the potential flow, a stable counterclockwise circulation is generated, and the wind direction dominates the surface layer. seriously affecting the flow field distribution in the reservoir area. The research results in this paper can provide support for the reservoir in the formulation of emergency water pollution emergency strategy and the formulation of real-time scheduling plan.
\end{abstract}

\section{Introduction}

Danjiangkou Reservoir is the water source of the Middle Route of the South-to-North Water Transfer Project, which spans the Hubei and Henan provinces, and is composed by the Hanjiang reservoir area in Hubei and the Danjiang reservoir area in Henan ${ }^{[1]}$ The average annual reservoir water volume of this reservoir is 39.5 billion $\mathrm{m}^{3}$, and the average annual area of the reservoir exceeds $700 \mathrm{~km}^{2[2]}$. At the same time, the Danjiangkou Reservoir is the water source for water diversion from the Middle Route of the South-to-North Water Transfer Project. The safety of water quality in the reservoir area is crucial $^{[3,}$ 4] Since the flow field is the main hydrodynamic factor for the migration of pollutants and suspended materials in the reservoir area, studying the impact of wind on the Danjiangkou Reservoir water flow field is particularly important for the water quality simulation in the reservoir area.

In recent decades, domestic scholars have carried out a large number of two-dimensional simulation studies on reservoirs and lakes ${ }^{[5-7]}$. Ma Shengwei et al. ${ }^{[8]}$ studied from the governing equations and based on the Galerkin finite element method ${ }^{[9]}$. The two-dimensional upwind finite element numerical model suitable for the

${ }^{\mathrm{a} C o r r e s p o n d i n g ~ a u t h o r: ~ E-m a i l ~ a d d r e s s: ~ j e a n q u a n @ 163 . c o m ~}$ calculation of wind-flow generation in shallow lakes is derived and analyzed. The morphological characteristics of the wind-flow field in Taihu Lake under the continuous action of uniform and steady wind field are analyzed. Ji Yong et $\mathrm{al}^{[10]}$ applied the Osher form two-dimensional flow numerical model of non-structure grid finite volume method to simulate the flow pattern of Xuanwu Lake in Nanjing under different wind conditions, and the characteristics of wind flow in the case of small throughput and no inflow along the coast are discussed. Lei Hongcheng, etc. ${ }^{[11]}$ established a two-dimensional water flow model by means of SMS surface water software, and studied the effects of different wind speeds and wind directions on the Dongping Lake water flow field. He Guofeng et $\mathrm{al}^{[12,}$ 13] combined with the topographical features of the lake, the hydrological and meteorological conditions, and the hydraulic principles under the normal design and temperature conditions of the upper lake in the Nansi Lake and established the mathematical model of water flow by Galerkin finite element method, and the influence of different wind conditions on the water flow field of the upper lake of Nansi Lake was studied. The above scholars' research shows that the wind has different degrees of influence on the flow field in the waters, but the previous studies have less involved the influence of the wind field on the hydrodynamics of the Danjiangkou reservoir. 
In this paper, with the help of environmental fluid dynamics model (EFDC), the effects of five different wind directions and two different wind speeds on the water flow field of Danjiangkou Reservoir under normal design water transfer conditions are studied. The research results in this paper can provide support for reservoirs in the formulation of emergency water pollution emergency strategies and real-time scheduling schemes.

\section{3-dimensional hydrodynamic model of Danjiangkou Reservoir}

\subsection{Control equation}

The EFDC model is based on the three-dimensional hydrodynamic equation ${ }^{[14]}$. The curve orthogonal transformation and $\sigma$ coordinate transformation are used in the horizontal and vertical directions respectively. The main control equation is:

The continuous equation:

$\frac{\partial m \zeta}{\partial t}+\frac{\partial\left(m_{y} H_{u}\right)}{\partial x}+\frac{\partial\left(m_{x} H_{v}\right)}{\partial y}+\frac{\partial(m w)}{\partial z}=Q_{H}$

Momentum equation:

$\frac{\partial\left(m H_{u}\right)}{\partial t}+\frac{\partial\left(m_{y} H_{u u}\right)}{\partial x}+\frac{\partial\left(m_{x} H_{v u}\right)}{\partial y}+\frac{\partial(m \omega u)}{\partial z}-\left(m f+v \frac{\partial m_{y}}{\partial x}-u \frac{m_{x}}{\partial y}\right) H_{v}$

$=-m_{y} H \frac{\partial(g \zeta+p)}{\partial x}-m_{y}\left(\frac{\partial h}{\partial x}-z \frac{\partial H}{\partial x}\right) \frac{\partial p}{\partial z}+\frac{\partial}{\partial z}\left(m \frac{1}{H} A_{v} \frac{\partial u}{\partial z}\right)+Q_{u}$

$\frac{\partial m H v}{\partial t}+\frac{\partial\left(m_{y} H u v\right)}{\partial x}+\frac{\partial\left(m_{x} H v v\right)}{\partial y}+\frac{\partial(m \omega v)}{\partial z}+\left(m f+v \frac{\partial m_{y}}{\partial x}-u \frac{\partial m_{x}}{\partial y}\right) H_{u}$

$=-m_{x} H \frac{\partial(g \zeta+p)}{\partial y}-m_{x}\left(\frac{\partial h}{\partial y}-z \frac{\partial H}{\partial y}\right) \frac{\partial p}{\partial z}+\frac{\partial}{\partial z}\left(m \frac{1}{H} A_{v} \frac{\partial v}{\partial z}\right)+Q_{1}$

Where: $\mathrm{z}=\left(\mathrm{z}^{*}+\mathrm{h}\right) / \mathrm{H}=(\mathrm{z} *+\mathrm{h}) /(\zeta+\mathrm{h}), \mathrm{z}$ ranges from $[0,1] ; z^{*}$ represents the actual vertical physical coordinates before $\sigma$ conversion, The total depth $\mathrm{H}=\mathrm{h}+$ $\zeta, \mathrm{h}$ is the bed elevation, $\zeta$ is the free surface elevation, $\mathrm{m}$; $\mathrm{u}$ and $\mathrm{v}$ are the velocity components in the $\mathrm{x}$ and $\mathrm{y}$ directions of the orthogonal coordinate system; $w$ is the vertical velocity at $\sigma$ coordinates; $m_{x}, m_{y}$ and $m$ are the Jacobian curve orthogonal coordinate conversion coefficients, $\mathrm{m}=m_{x} m_{y} ; Q_{H}$ is rainfall, evaporation, groundwater interaction, water abstraction or point source and non-point source inflow; $p$ is the relative hydrostatic pressure; $f$ is the Coriolis force parameter; $A_{v}$ is the turbulent viscous coefficient of the vertical turbulence; Qu and Qv are the momentum source terms.

\subsection{Research area and meshing}

Danjiangkou Reservoir is located in the middle and upper reaches of the Han River and is distributed in Danjiangkou City of Hubei Province and Nanyang City of Henan Province. It is divided into Hanjiang Reservoir Area and Danjiang Reservoir Area. The average annual inflow of Danjiangkou Reservoir is 39.48 billion $\mathrm{m}^{3}$, and the water source comes from the Han River and the tributary Danjiang. The average annual area of the reservoir is $700 \mathrm{~km}^{2}$. After the Danjiangkou dam is raised in 2012, the water area of the Danjiangkou Reservoir will reach $1022.75 \mathrm{~km}^{2}$ and the water storage capacity will reach 29.05 billion $\mathrm{m}^{3[15,16]}$.

According to the topographical and boundary variation characteristics of the reservoir area, the grid is divided into rectangular grid structures with a grid size of $500 \mathrm{~m} \times 500 \mathrm{~m}$ and a total of 2155 rectangular grids. In the vertical 6-story, considering that the measured data is measured from $0.5 \mathrm{~m}$ below the surface to $0.5 \mathrm{~m}$ above the bottom of the reservoir, the ratio from the bottom of the intermediate water depth to the top 6 is $0.1 .0 .15,0.25$, $0.25,0.15,0.1$, which ensures the accuracy of the vertical simulation and better fits the actual monitoring value ${ }^{[17]}$. The specific mesh is shown in Fig. 1.

\subsection{Boundary conditions and initial conditions}

According to the normal design water transfer conditions given in the first phase of the South-to-North Water Transfer Project, this paper sets 4 flow boundaries (3 inflow boundaries and 1 outflow boundary (Danjiangkou dam)), 1 water level boundary and 1 simulation monitoring point $\mathrm{A}$. The specific locations are shown in Fig. 1

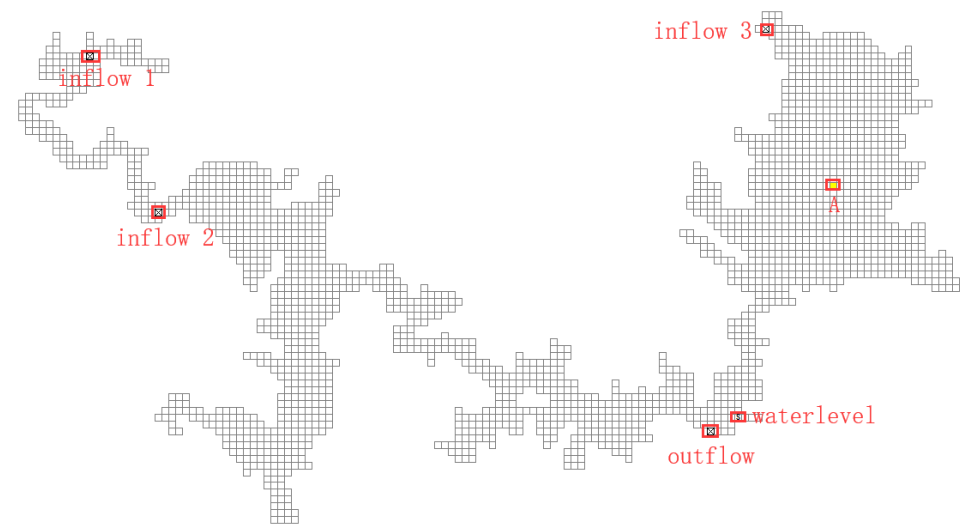

Fig. 1 Boundary point position

According to the meteorological data of Danjiangkou Reservoir in 2012, the wind direction of the reservoir area is: southeast wind, east wind and south wind in summer, and north wind and north wind in winter, and the wind level is mainly 2 or 3 . In this paper, the wind direction is selected as windless (C), Dongfeng (E), 
southeast wind (SE), and south wind (S) northeast wind (NE). The wind speed is $3.3 \mathrm{~m} / \mathrm{s}$ and $10.0 \mathrm{~m} / \mathrm{s}$ respectively. The simulated calculation conditions are shown in Table 1 .

The simulation calculation time is from July 2, 2012 to August 2, 2012, and the time step is 20s. Considering that there is no flow field data at the initial time, the initial flow field full field velocity is firstly set to 0 , and the initial flow field water level is $145 \mathrm{~m}$.

Table 1 simulated working conditions

\begin{tabular}{ccc}
\hline working condition & Wind direction & Wind speed $(\mathrm{m} / \mathrm{s})$ \\
\hline 1 & $\mathrm{C}$ & 0 \\
2 & $\mathrm{E}$ & 3.3 \\
3 & $\mathrm{E}$ & 10 \\
4 & $\mathrm{~S}$ & $3 . .3$ \\
5 & $\mathrm{~S}$ & 10 \\
6 & $\mathrm{SE}$ & 3.3 \\
7 & $\mathrm{SE}$ & 10 \\
8 & $\mathrm{NE}$ & 3.3 \\
9 & $\mathrm{NE}$ & 10 \\
\hline
\end{tabular}

are shown in Fig. 2. It can be seen from Fig. 2 that in the

\section{Flow field simulation results and analysis}

\subsection{Analysis of simulation results of water flow field windless}

The change of the Danjiangkou Reservoir water flow field is mainly affected by the Danjiang River, the Han River inflow and the dam front outflow. In 2012, the flow field of the Danjiangkou Reservoir changed greatly. The distribution results of the surface water transport flow field under normal design and water transfer conditions situation of windless, the overall shape of the flow field in the reservoir area is similar to the potential flow, that is, flowing along the three inflow points toward the outflow point. There is no obvious circulation distribution and stagnant water area in the reservoir area; the area with large surface water transport rate is mainly concentrated in the inflow port of the reservoir area and the narrow area near the outlet, and the maximum surface velocity appears at the inlet of the Hanjiang reservoir area, and the minimum flow velocity of the surface layer mainly occurs on the border.

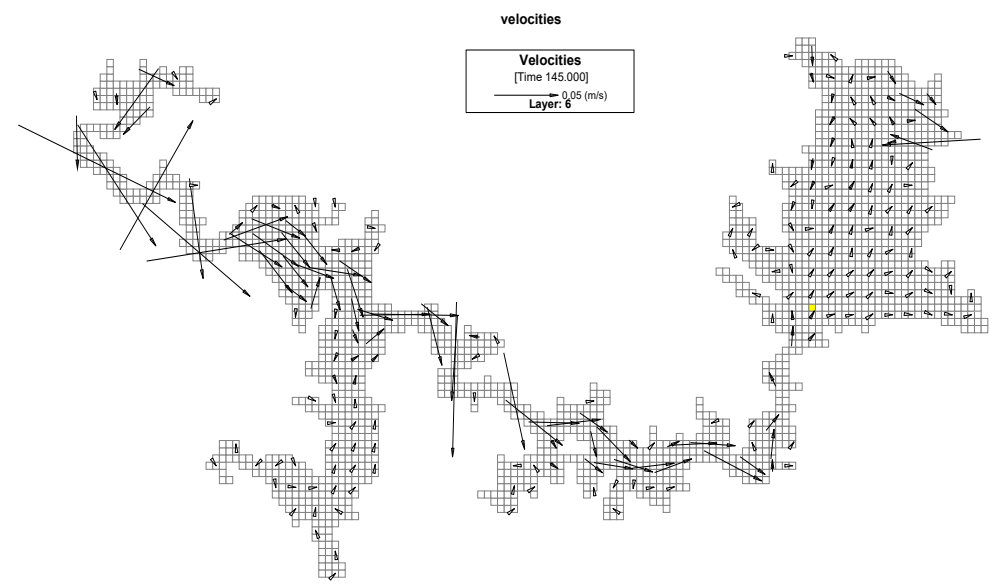

Fig. $2 \mathrm{C}$

\subsection{Water flow field at a wind speed of $3.3 \mathrm{~m} / \mathrm{s}$}

Fig. 3(a-d) shows the distribution of the surface water flow field in the reservoir area under normal design water transfer conditions with a wind speed of $3.3 \mathrm{~m} / \mathrm{s}$. It can be seen from Fig. 3(a-d) that at the wind speed of $3.3 \mathrm{~m} / \mathrm{s}$, the surface velocity of the reservoir area is increased compared with the windless condition, and the surface flow velocity under the southerly wind is more obvious
(Fig. 3: b). The area with large flow velocity is mainly occurred in the inflow port of the reservoir area and the narrow area near the outflow port, which is not conducive to the occurrence of eutrophication. The minimum flow velocity of the surface layer is concentrated near the boundary; under the action of the wind field, the water flow in the reservoir area. The direction of the field is offset, and its direction is affected by the wind direction. The easterly and northeast winds with the same direction of the potential flow have less 
influence on the flow direction (Fig. 3: a, d), and the southerly and southeast opposite to the direction of the potential flow. The influence of wind on the flow direction is large (Fig. 3: b, c), but the offset angle is small and the flow direction angle is unstable, which leads to the disorder of the flow field in the reservoir area; the small circulation occurs locally in the reservoir area, which aggravates the water flow. The mixing phenomenon improves the water exchange capacity, and the circulation is mainly concentrated in the relatively wide Danjiang reservoir area. Under the action of the east wind and the northeast wind, the circulation in the reservoir area is not obvious (Fig. 3: a, d). Under the influence of the south wind and the southeast wind, the formation of small clockwise circulation in the reservoir area is relatively obvious (Fig. 3: b, c). Compared with windless condition, the $3.3 \mathrm{~m} / \mathrm{s}$ wind field affects the distribution of the water flow field in the reservoir area. The water transfer in the reservoir area has some effects, but the water transfer project can operate normally.

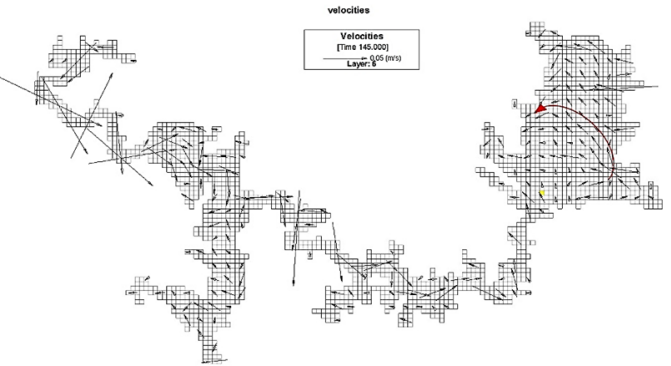

(a) $3.3 \mathrm{~m} / \mathrm{s}, \mathrm{E}$

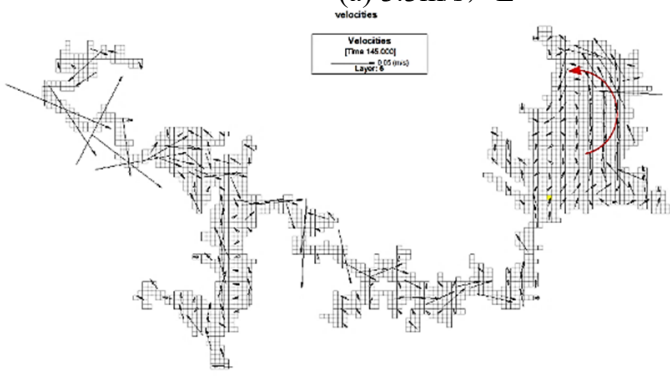

(c) $3.3 \mathrm{~m} / \mathrm{s}, \mathrm{SE}$

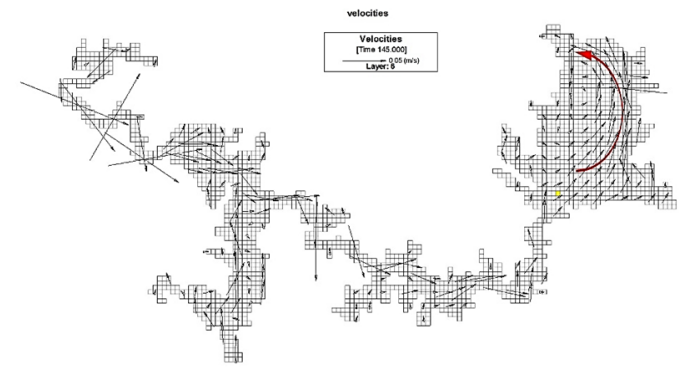

(b) $3.3 \mathrm{~m} / \mathrm{s}, \quad \mathrm{S}$

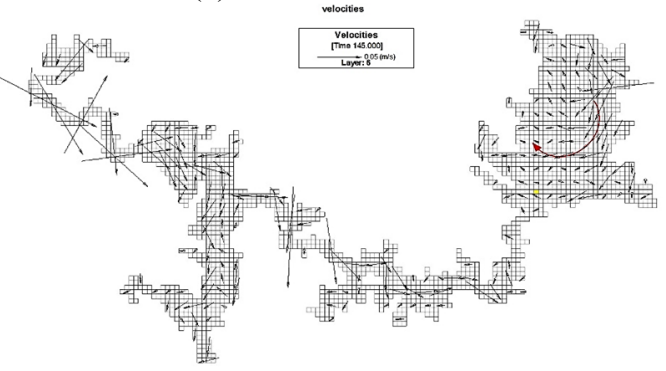

(d) $3.3 \mathrm{~m} / \mathrm{s}, \quad \mathrm{NE}$

Fig. 3 Flow field at $3.3 \mathrm{~m} / \mathrm{s}$ wind speed

\subsection{Analysis of water flow field and point $A$ simulation results when wind speed is $10 \mathrm{~m} / \mathrm{s}$}

Fig. 4 (a-d) shows the distribution of the water flow field in the reservoir area at a wind speed of $10 \mathrm{~m} / \mathrm{s}$ under normal design water transfer conditions. It can be seen from Fig. 4(ad) that when the wind speed increases to $10.0 \mathrm{~m} / \mathrm{s}$, the surface velocity of the reservoir area increases significantly, and the difference of the velocity of the different regions becomes smaller. The surface of the reservoir area under the action of the southerly wind, the southeast wind and the northeast wind, the flow rate increase is more significant (Fig. 4: b, c, d). The difference in flow velocity between different areas of the reservoir area under the action of easterly wind is smaller (Fig. 4: a); the flow field in the reservoir area is almost completely controlled by the wind direction, and the east wind The overall surface flow of the flow field in the reservoir area under the influence of southerly wind, southeast wind and northeast wind is west, north, southwest and south respectively (Fig. 4: a, b, c, d), except for Danjiang reservoir area; wind field drives water flow The circulation in the reservoir area is more significant and the range is larger. There are significant large circulations from the local small circulation to the Danjiangkou reservoir area, and the circulation is relatively stable and the flow direction angle is small. The wind direction also affects the circulation direction and circulation pattern. The circulation of the Danjiang reservoir area in the wide watershed is more pronounced. The southerly wind and the southeast wind produce a stable counterclockwise circulation (Fig. 4: b, c). The northeast wind produces a stable clockwise circulation (Fig. 4: d). The direction of the circulation is not stable, but the flow angle wave Small (Fig. 4: a). The results show that compared with the windless condition, the overall distribution of the water flow field in the reservoir area changes greatly when the wind field is 10 $\mathrm{m} / \mathrm{s}$. The wind direction becomes the dominant factor in the flow direction of the reservoir area. 


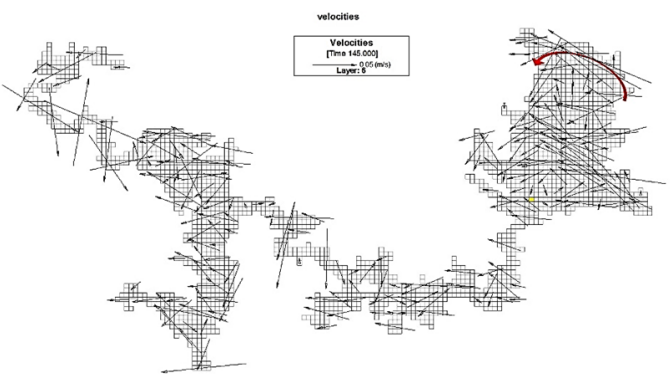

(a) $10.0 \mathrm{~m} / \mathrm{s}, \mathrm{E}$

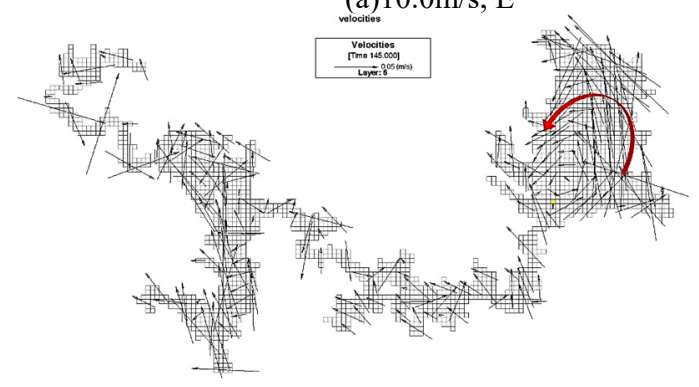

(c) $10.0 \mathrm{~m} / \mathrm{s}, \mathrm{SE}$

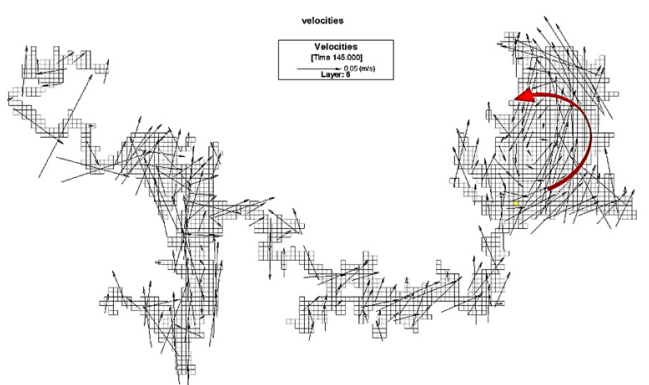

(b) $10.0 \mathrm{~m} / \mathrm{s}, \mathrm{S}$

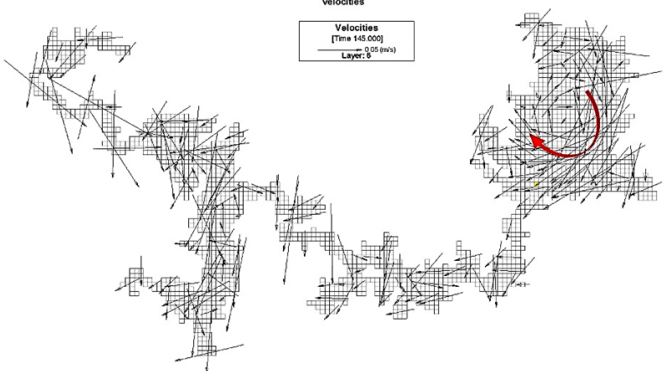

(d) $10.0 \mathrm{~m} / \mathrm{s}, \mathrm{NE}$

Fig. 4 Flow field at $10.0 \mathrm{~m} / \mathrm{s}$ wind speed

\subsection{Simulation monitoring results at point $A$ of the circulation area}

Based on the qualitative analysis of the flow field in the Danjiangkou reservoir area under five different wind directions and two different wind speed conditions, this paper selects the surface point A of the relatively significant circulation area in the reservoir area (Danjiang reservoir area) for flow velocity and Quantitative monitoring of flow direction. Fig. 5 to 6 show the simulation results of the flow rate and flow direction of point $\mathrm{A}$.

From the simulation results and simulation values of flow velocity and flow direction at point A (Fig. 5 6), the wind field has a great influence on the distribution of flow field in the reservoir area. When the wind speed is $3.3 \mathrm{~m} / \mathrm{s}$, and under the influence of easterly wind and southeast wind, point A maximum flow velocity is 1.4 1.7 times when there is windless, and the average flow velocity is increased to 3 4 times when there is windless. Under the action of southerly wind and northeast wind, the maximum flow velocity at point $A$ is 1.5 1.9 times when there is windless. The average flow velocity increases to 5 times when there is windless; when the wind speed increases to $10.0 \mathrm{~m} / \mathrm{s}$, the maximum flow velocity at point $A$ is 4.4 to 5.1 times when there is windless under the action of easterly wind and southeast wind, and the average flow velocity increases to none. 19 times of wind; under the action of southerly wind and northeast wind, the maximum flow velocity at point $A$ is 5.6 6.1 times when there is windless, and the average flow velocity is increased to 23 times when there is windless. Through the analysis of the flow field in the windless reservoir area, the wind field will increase the flow velocity of the reservoir, change the flow direction, and generate circulation. The higher the wind speed, the more significant the change of the reservoir area, among which the south wind and the northeast wind. The impact of the reservoir area is more significant.

It can be seen from Fig. 5 6 that the flow velocity and flow direction at point $\mathrm{A}$ from 1 st to 7 th days in the simulation calculation period are relatively stable, the flow velocity value is 8th-14th days, and the flow velocity and flow direction at point A of 15th-31st days are relatively stable. The temporal evolution of the wind-flow stream in the Danjiangkou Reservoir has similar characteristics: in the early stage of the wind field, the dragging effect of the wind on the reservoir water dominates; then, the pressure gradient force and the Coriolis force of the water level gradually increase, and the flow field gradually deflects, and then The compensation flow or the circulation is formed; when the steady state is reached, the shear stress of the wind, the pressure gradient force of the water level, the Coriolis force, and the internal friction reach a balance.

The results show that the initial time from the simulation of the reservoir area to the steady state can be divided into three stages: in the first stage, the flow direction of the flow field is consistent with the wind direction, and the shear stress of the wind surface is in the equation of the model. Dominant, this feature can be maintained for up to 7 days; in the second stage, the flow direction of the coastal area is basically consistent with the wind direction, and the compensation flow opposite to the wind direction appears in the reservoir area, and the flow field distribution fluctuates slightly; The compensation flow in the near windward bank area has gradually strengthened, and the water flow compensation or flow direction shift has occurred in the reservoir area as a whole, and the circulation area has gradually formed. After about 15 days, the circulation patterns of these circulation areas are stabilized and remain unchanged. 

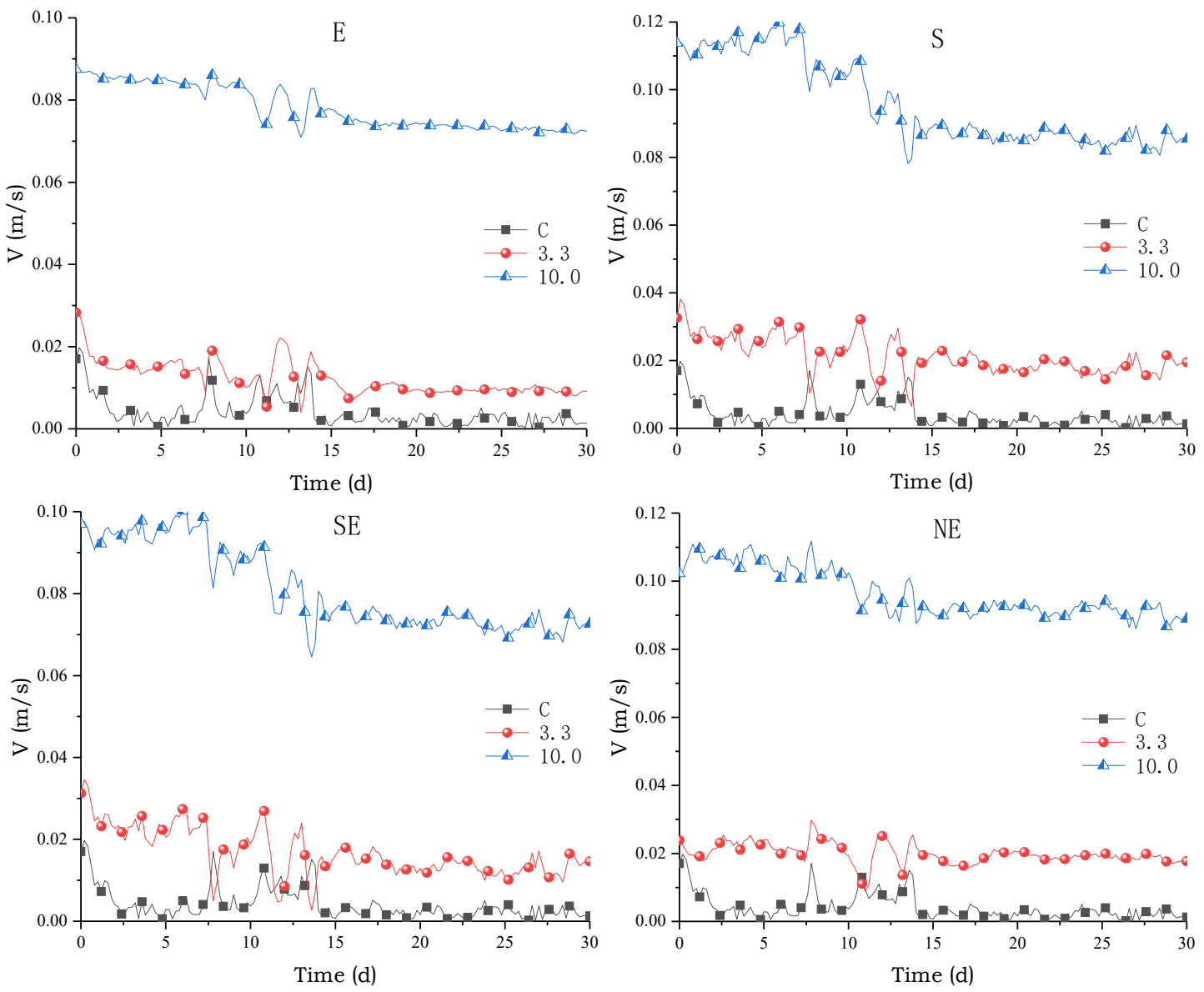

Fig. 5 The calculation of the flow velocity of the A point
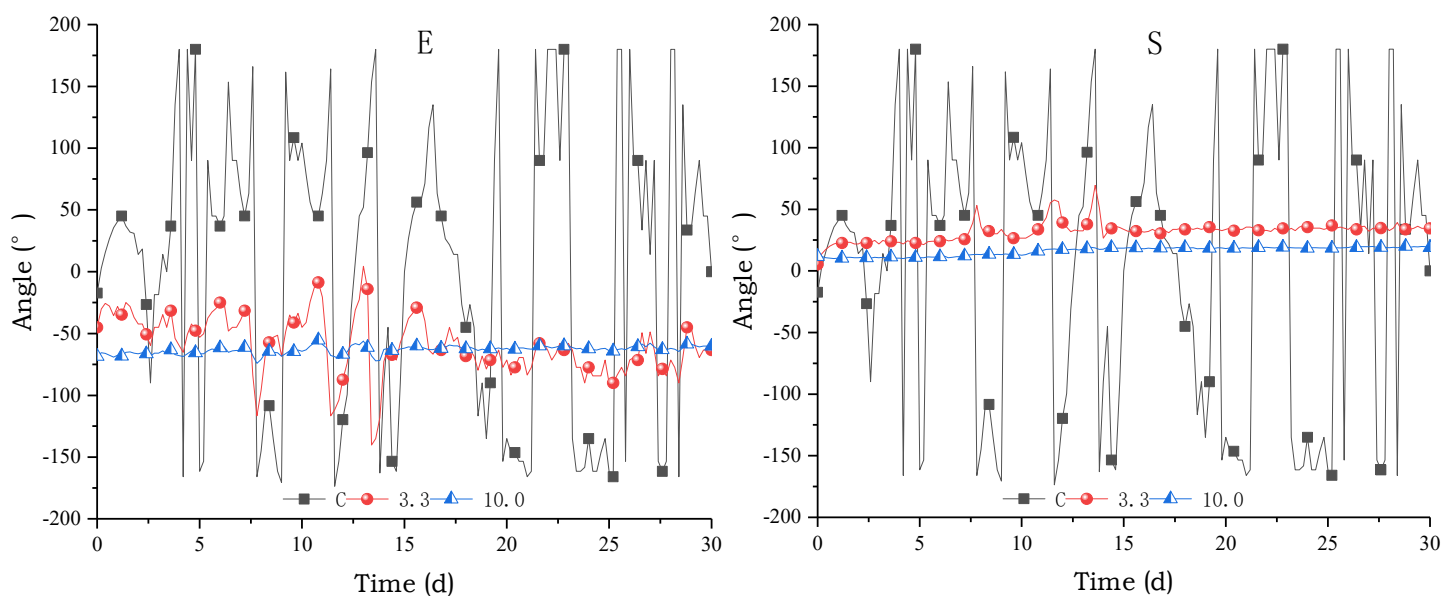

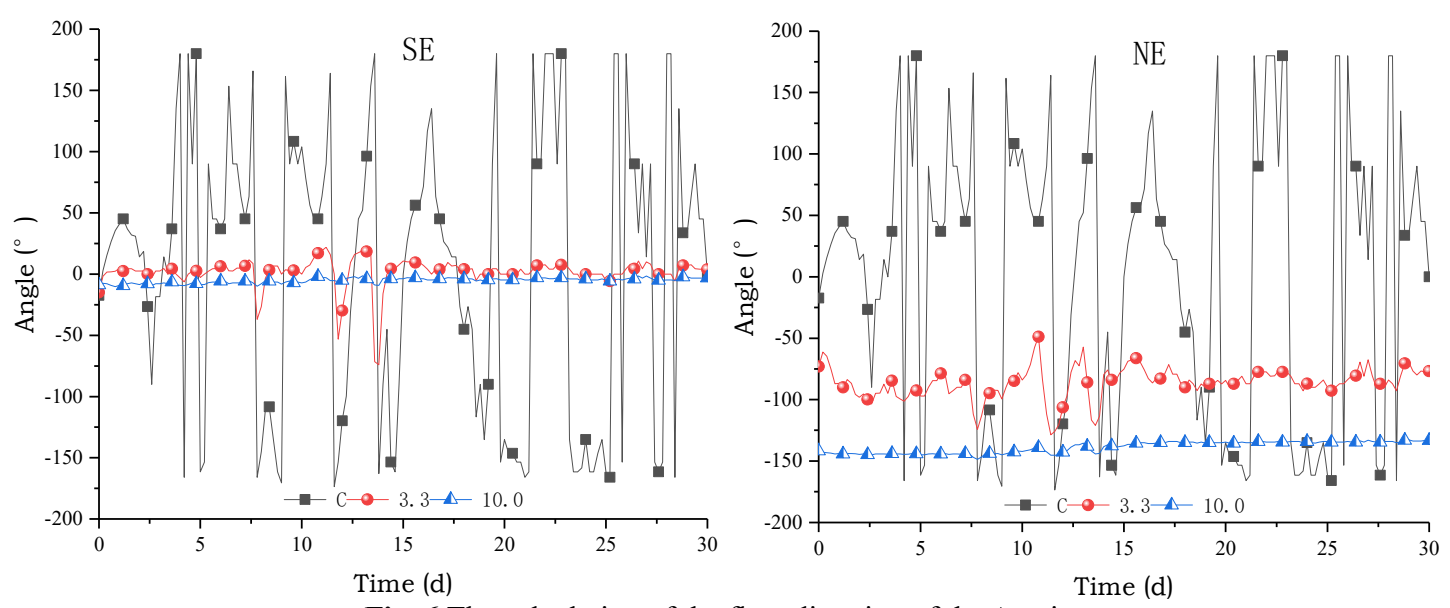

Fig. 6 The calculation of the flow direction of the A point

\section{Conclusion}

According to the meteorological and hydrological data analysis of the Danjiangkou Reservoir in 2012, this paper establishes a three-dimensional hydrodynamic model of the Danjiangkou Reservoir based on the EFDC model, and studies the water flow field distributions in the reservoir area under two different wind speeds and five different wind directions. The flow velocity of the measuring point $\mathrm{A}$ was also studied. The following conclusions were drawn:

(1) Under the influence of wind field with wind speed (wind speed of $3.3 \mathrm{~m} / \mathrm{s}$ ), the surface velocity of the reservoir area increases slightly. Under the same wind condition as the direction of the potential flow, the change of surface flow velocity and surface flow direction is small; Under the action of the wind direction opposite to the direction of the potential flow, the direction of the flow field in the reservoir area shifts slightly with the change of the wind direction, the offset angle is not large, the surface flow direction is disordered, and the small circulation is generated locally in the reservoir area, and the circulation range is small. Therefore, the wind field with a general wind speed (wind speed of $3.3 \mathrm{~m} / \mathrm{s}$ ) has little effect on the flow field of the Danjiangkou Reservoir under normal design water transfer conditions. The water quality (solute pollutants) in the reservoir area can be considered without considering the wind. influences.

(2) When the wind speed is high (wind speed is $10.0 \mathrm{~m} / \mathrm{s}$ ), the surface velocity of the water flow field in the reservoir area increases significantly with the increase of wind speed; the circulation pattern in the reservoir area is more significant, in the same wind direction as the potential flow direction. Under the action, the reservoir area produces a stable clockwise circulation; under the action of the wind direction opposite to the direction of the potential flow, a stable counterclockwise circulation is generated; the circulation range of the reservoir area is increased; and the dominant flow direction of the water conveyance flow field in the reservoir area is changed. Under the action of the wind condition opposite to the direction of the potential flow, the wind direction becomes the dominant factor controlling the surface flow direction of the water flow field in the reservoir area. The wind effect enhances the convection and turbulence of the reservoir water, thereby affecting the transport of sediment in the lake, the diffusion of pollutants and the migration of plankton. Therefore, it is necessary to consider the effect of wind when simulating the water quality (solute pollutants) in the reservoir area under conditions of large wind speed (wind speed up to $10.0 \mathrm{~m} / \mathrm{s}$ ).

\section{Acknowledgements}

This paper was supported by the Major Science and Technology Program for Water Pollution Control and Treatment (2017ZX07108-001).

\section{Reference}

1. J. Y. Wang, Y. C. Lin, Discussion on Water Pollution Factors and Prevention Measures of Water Sources in the Middle Route of South-to-North Water Transfer Project of Henan Province. Henan Water Conservancy, 8-13 (2005).

2. W. Y. Zhao, Present Situation of Ecological Environment Protection in Danjiangkou Reservoir Basin. The People's Yangtze River 37, 112-114 (2006).

3. W. Z. Liu, H. M. Bu, G. H. Liu, Study on the Response of Wetland Vegetation in Danjiangkou Reservoir Area to the Middle Route of South-to-North Water Transfer Project.Bulletin of Soil and Water Conservation, 149-152 (2009).

4. S. Y. Li, Q. F. Zhang, Using water quality index method to evaluate the water quality of Danjiangkou Reservoir in the middle water source of South-to-North Water Transfer Project. Environmental Science Research, 61-68 (2008).

5. Y. Wang, H. Wang, W. Ji, Experimental study on hydrodynamic characteristics of wind-induced flow. South-to-North Water Transfer and Water Conservancy Science and Technology, 122-126 (2018). 
6. J. X. Wu, Z. W. Fan, M. Zhang, Numerical simulation of wind-induced flow intensity in shallow lakes and its engineering application. Hydropower Science, 119-122 (2014).

7. F. Hosseinibalam, S. Hassanzadeh, A. Rezaei-Latifi, Three-dimensional numerical modeling of thermohaline and wind-driven circulations in the Persian Gulf. Applied Mathematical Modelling 35, 5884-5902 (2011)

8. S. W. Ma, Q. M. Cai, Study on Upwind Finite Element Numerical Model of Wind-induced Flow in Shallow Lakes. Advances in Water Science, 70-75 (2000).

9. J. C. Zhang, Jilin University, (2017).

10. Y. Ji, J. Zhang, R. B. Zhang, Numerical Simulation of Wind-induced Flow in Typical Urban Lakes. Water Science and Engineering Technology, 57-59 (2005).

11. H. C. Lou, Z. H. Wu, Z. T. Yang, Simulation of the Influence of Wind on the Flow Field of Dongping Lake in the East Route of South-to-North Water
Transfer Project. Hydropower Science, 123-126 (2014).

12. G. F. He, Z. H. Wu, in National Symposium on Environmental and Ecological Hydraulics. (2008).

13. G. F. He, Qingdao Technological University, (2009).

14. Y. Wang, $\mathrm{H}$ Wang, Y. Jiang, e. al, 3-D hydro-environmental simulation of Miyun reservoir, Beijin. Journal of Hydro-environment Research $\mathbf{8}$, 383-395 (2014).

15. Y. Duan, T. Qin, J. J. Wang, Three dimensional hydrodynamic simulation of Danjiangkou reservoir. people the Yellow River, 119-122 (2018).

16. Y. Duan, China University of Geosciences (Beijing), (2014).

17. H. Z. Zheng, Y. Shang, Y. Duan, Sudden Water Pollution Accidents and Reservoir Emergency Operations Impact Analysis at Danjiangkou Reservoir Environmental Technology 39, 1-16 (2017). 